\title{
Experimental studies on seed production of tropical grasses in Kenya. 2. Tillering and heading in seed crops of eight grasses
}

\author{
J. G. Boonman
}

National Agricultural Research Station, Kitale, Kenya

Received: 15 July 1971

\section{Summary}

Tillering in seed crops grown undisturbed for six months was studied over two years in varieties of Setaria sphacelata, Chloris gayana, Panicum coloratum, Panicum maximum and Brachiaria ruziziensis. Tiller numbers rose to a maximum around the time of initial head emergence (IHE) (5-10 heads per $\mathrm{m}^{2}$ ), followed by a decline and finally a levelling off. Head emergence was found to continue in some varieties for over threc months. The weight per tiller increased at a linear rate. Tiller numbers never exceeded 1900 per $\mathrm{m}^{2}$. In the year of planting, tillers were less numerous but heavier than in the subsequent year. Total dry weights of tillers were also highest in the first year.

Seed yield was significantly correlated with degree of concentrated head emergence and percentage of heading tillers in a variety. It is suggested that, within varieties, plants with heavier tillers may produce higher seed yields. Varieties within species can be identified according to date of IHE.

A type of culm branching is described whereby tillers develop into flowering culms out of elevated nodes of erect parental culms.

\section{Introduction}

In a previous paper (Boonman, 1971) various factors limiting seed yield of tropical grasses in Kenya were listed. It was indicated that prolonged heading, which may last over three months, was an important factor reducing seed yield.

The present study attempts to elucidate the heading pattern of some contrasting va. rieties by following the tillering behaviour under crop conditions. As shown in work with temperate grasses, knowledge of tillering is important for a better understanding of the seed crop (Ryle, 1966).

Numerous studies are available on tillering in temperate grasses, which have been reviewed by Langer (1963), Humphreys (1966a) and Dorrington Williams (1970). Reports on tillering in cultivated tropical grasses are, however, only very few (Humphreys. 1966b; Haggar, 1966; Singh and Chatterjee, 1966; Chatterjee and Singh, 1968).

\section{Materials and methods}

The following varieties were planted from seed on 9 April 1968 in adjacent plots

Setaria sphacelata cv. 'Nandi I'

Setaria sphacelata cv. 'Nandi III'

Chloris gayana cv. 'Mbarara'
Common name

Nandi I

Nandi III

Mbarara Rhodes 


$\begin{array}{ll}\text { Chloris gayana cv. 'Masaba' } & \text { Masaba Rhodes } \\ \text { Chloris gayana cv. 'Pokot' } & \text { Pokot Rhodes } \\ \text { Panicum coloratum cv. 'Solai' } & \text { Coloured Guinea } \\ \text { Panicum maximum cv. 'Makueni' } & \text { Makueni Guinea } \\ \text { Brachiaria ruziziensis } & \text { Congo Signal }\end{array}$

Since the plots were more than $500 \mathrm{~m}^{2}$ in size, they could not be laid out in a compact block on the narrow terrace reserved for this study. In the design used, the distance between any two fields did not exceed $200 \mathrm{~m}$.

Seed at a rate equivalent to $1 \mathrm{~kg}$ per ha Pure Germinating Seed (PGS) was mixed with single superphosphate at $40 \mathrm{~kg} \mathrm{P}_{2} \mathrm{O}_{5}$ per ha and planted in rows $75 \mathrm{~cm}$ apart. The number of rows of each entry in the investigation was 30 , not including some guard rows at the edges. As no uniform row length could be adopted on account of the varying width of the terrace, rows were $29 \mathrm{~m}$ long in Nandi, $24 \mathrm{~m}$ in Rhodes and only $19 \mathrm{~m}$ in the other varieties. The fields were subdivided into replicates running across the direction of rows. Owing to the varying row length, four replicates were imposed on the fields with $19 \mathrm{~m}$ rows and five on those of 24 and $29 \mathrm{~m}$ rows. The length of row within each replicate was 3,4 and $5 \mathrm{~m}$, respectively.

During 1968, only the top replicate was used for observations on tillering, the other replicates being set aside for concurrent determinations of seed yield at various harvesting times. Only seed yields obtained at the optimum harvesting time will be reported here. In the top replicate, in each of 4 plots consisting of 4 rows, portions of undisturbed $50 \mathrm{~cm}$ row length were cut at weekly intervals for a period of 12 weeks. The sampling procedure involved the cutting of tillers just above ground level, separating into heading and non-heading tillers, counting, oven-drying and weighing. Sampling for tillering commenced when the first variety, Panicum coloratum, began heading, on 8 July, 13 weeks after planting, and was discontinued 11 weeks later on 23 September.

In 1969, another method of sampling was adopted when it was observed that the 1968 method of cutting adversely affected subsequent regrowth or even killed plants, probably due to low cutting and competition from the surrounding undisturbed crop. The cleaning cut and subsequent top dressing with $50 \mathrm{~kg} \mathrm{~N}$ as ammonium sulphate nitrate per ha was carried out on 9 May. The cleaning cut was meant to remove the growth that had developed after a previous cleaning cut on 21 March on which date a top dressing had been given of $40 \mathrm{~kg} \mathrm{P}_{2} \mathrm{O}_{5}$ per ha and $50 \mathrm{~kg} \mathrm{~N}$ per ha. Counting of tillers began on 12 May, three days after the cleaning cut. The tiller counts were carried out weekly in situ in sections of $25 \mathrm{~cm}$ row length at 12 random sites over the whole field. Every week 12 new sites were taken.

After counting in situ, numerous sections of less than $5 \mathrm{~cm}$ row length were cut as low as possible. These samples were mixed together; loose leaves and dead material were removed and 3 samples of 100 tillers were chosen at random, oven-dried and weighed separately. On 9 June, the fifth sampling date, crop growth became too heavy and dense for further tiller counts in situ, and no alternative was left but to revert to the method used in 1968, although four extra samples were now taken in the other replicates giving a total of eight. In July and August, samples were taken once every two weeks and in September and October once every three weeks. The sampling period covered 24 weeks.

For the purpose of this experiment the total number of tillers was divided into two categories:

- heading tillers; these are tillers in which heads have fully emerged, the dividing point 
Table 1. Official rainfall figures (mm) for Kitale over 1968 and 1969.

\begin{tabular}{|c|c|c|c|c|c|c|c|c|c|c|c|c|}
\hline \multirow[t]{2}{*}{ Year } & \multicolumn{12}{|c|}{ Month } \\
\hline & 1 & 2 & 3 & 4 & 5 & 6 & 7 & 8 & 9 & 10 & 11 & 12 \\
\hline 1968 & 1 & 147 & 69 & 201 & 95 & 127 & 176 & 121 & 60 & 88 & 57 & 18 \\
\hline 1969 & 62 & 58 & 107 & 54 & 215 & 49 & 101 & 176 & 116 & 119 & 52 & 6 \\
\hline
\end{tabular}

being when the base of the head is visibly free from the leaf sheath.

- non-heading tillers; any type of tiller that has not produced an emerged head.

Unless stated otherwise, the term tiller will hereafter refer only to the overall number unless a specification of heading or non-heading is given.

In view of the scope of this study, no attempt was made to dissect tillers for the detection of flower initiation. The above classification is therefore used instead of one which divides them into vegetative and generative, or fertile and sterile tillers.

The official rainfall figures in $\mathrm{mm}$ for Kitale over the two years under review are given in Table 1.

\section{Results}

Data on numbers and weights of non-heading and heading tillers were obtained in all eight varieties over 1968 and 1969. Only essential data are presented here, but the complete set can be obtained from the author upon request.

The data on time of Initial Head Emergence (IHE), maximum tiller numbers and weights are shown in Tables 2, 3, 4 and 5. In Fig. 1 the tillering patterns of three characteristic varieties in 1969 are shown. Fig. 2 presents the head emergence curves of all varieties for both years. Table 6 and Fig. 3 show the correlation between seed yield and tillering and heading characteristics. In Fig. 4 a presentation is given of the mean culm length as heading proceeds.

\section{Time of Initial Head Emergence (IHE)}

The time of IHE is defined as the time when 5-10 heads have emerged per $\mathrm{m}^{2}$. The data of 1968 and 1969 are shown in Table 2. Also those of 1970 were added because observations on IHE were continued in that year.

Table 2. Sequence in time of initial head emergence (IHE) over weekly intervals.

\begin{tabular}{llll}
\hline Variety & 1968 & 1969 & 1970 \\
Nandi I & 3 & 4 & 4 \\
Nandi III & 6 & 6 & 5 \\
Mbarara Rhodes & 2 & 1 & 3 \\
Masaba Rhodes & 3 & 2 & 6 \\
Pokot Rhodes & 5 & 3 & 7 \\
Coloured Guinea & 1 & 2 & 1 \\
Makueni Guinea & 5 & 1 & 3 \\
Congo Signal & 8 & 1 & 12 \\
\hline
\end{tabular}


Within columns, each value indicates the week in which the particular variety showed IHE, the earliest variety bearing the value 1 . No calendar dates are given because heading did not start in the same month each year due to differences in date of cleaning cut and because in the year of planting IHE is usually a few months later than in subsequent years.

Coloured Guinea was consistently among the first varieties to show IHE, followed by Mbarara Rhodes. Makueni Guinea was early in 1969 and 1970 but not in the year of planting (1968). This variety is known to be the most drought-tolerant variety in the range under review and as a result it may develop quicker after the onset of the rains; on the other hand it is known to establish slow from seed under Kitale conditions. Pokot Rhodes and Nandi III were late heading varieties. Congo Signal behaved erratically. It is further evident that Nandi I showed IHE 1-3 weeks earlier than Nandi III and that Mbarara Rhodes was earlier than Masaba and Pokot Rhodes, the latter being latest. It was not possible to discern a clear sequence among the species themselves, although Nandi appeared to be a late group.

\section{Numbers of tillers and heads}

In both years, tiller numbers rose to a maximum that coincided roughly with the time of IHE. In 1969 maximum numbers were attained within 2-6 weeks after the cleaning cut and in 1968 14-19 weeks after planting, depending on the variety.

In the year of planting, maximum numbers were often less than half of those of the subsequent year and varied from 560 per $\mathrm{m}^{2}$ in Pokot Rhodes to 800 in Nandi III (Table 3). In 1969, maximum numbers varied from 1280 in Congo Signal to 1920 per $\mathrm{m}^{2}$ in Nandi III. Thus Nandi III produced the highest number of tillers in both years, followed by Mbarara and Masaba Rhodes. Consequently, Nandi III produced more tillers than Nandi I, while Mbarara and Masaba Rhodes produced more than Pokot Rhodes.

In Fig. 1 tillering curves are presented for three varieties in 1969, representing three different combinations of herbage and seeding properties. Nandi III is known to be a good pasture grass, but a poor seeder. In contrast, the opposite applies to Coloured Guinea. Mbarara Rhodes, however, combines good herbage with good seeding proper-

Table 3. Numbers of tillers and heading tillers (heads).

\begin{tabular}{|c|c|c|c|c|c|c|c|c|}
\hline \multirow[t]{2}{*}{ Variety } & \multicolumn{4}{|l|}{1968} & \multicolumn{4}{|l|}{1969} \\
\hline & $\begin{array}{l}\text { maximum } \\
\text { number } \\
\text { of tillers } \\
\text { per } \mathrm{m}^{2}\end{array}$ & $\begin{array}{l}\text { maximum } \\
\text { number } \\
\text { of heading } \\
\text { tillers } \\
\text { per } \mathrm{m}^{2}\end{array}$ & $\%$ & $\begin{array}{l}\text { heading } \\
\text { tillers at } \\
\text { final sam- } \\
\text { pling (\%) }\end{array}$ & $\begin{array}{l}\text { maximum } \\
\text { number } \\
\text { of tillers } \\
\text { per } \mathrm{m}^{2}\end{array}$ & $\begin{array}{l}\text { maximum } \\
\text { number } \\
\text { of heading } \\
\text { tillers } \\
\text { per } \mathrm{m}^{2}\end{array}$ & $\%$ & $\begin{array}{l}\text { heading } \\
\text { tillers at } \\
\text { final sam- } \\
\text { pling }(\%)\end{array}$ \\
\hline Nandi I & 620 & 120 & 19 & 27 & 1,400 & 350 & 25 & 57 \\
\hline Nandi III & 800 & 90 & 11 & 18 & 1,920 & 170 & 9 & 19 \\
\hline Mbarara Rhodes & 790 & 210 & 27 & 33 & 1,610 & 320 & 20 & 31 \\
\hline Masaba Rhodes & 700 & 260 & 37 & 53 & 1,800 & 230 & 13 & 39 \\
\hline Pokot Rhodes & 560 & 110 & 20 & 38 & 1,380 & 160 & 12 & 29 \\
\hline Coloured Guinea & 610 & 390 & 64 & 77 & 1,530 & 520 & 34 & 76 \\
\hline Makueni Guinea & 600 & 70 & 12 & 18 & 1,330 & 130 & 10 & 45 \\
\hline Congo Signal & 690 & 220 & 32 & 50 & 1,280 & 470 & 37 & 78 \\
\hline
\end{tabular}




\section{Number of tillers}

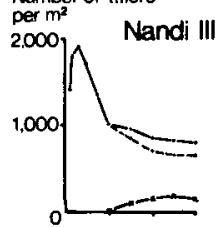

Dry weight of

tillers $(\mathrm{kg} / \mathrm{ha})$

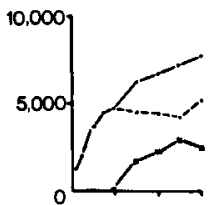

Dry weight

per tiller (mg)

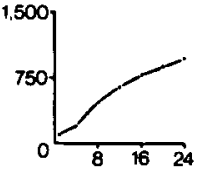

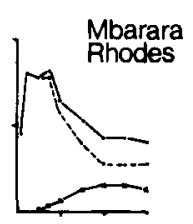

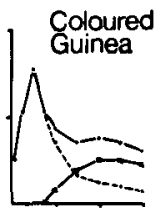

Fig. 1. The tillering patterns of three varieties in $1969 ;. \ldots$ total of all tillers, including non-heading tillers; ..- - non-heading tillers; $\mathbf{x}-\mathbf{x}$ heading tillers.

ties. The tillering patterns of these three varieties were basically the same in both years and, in fact, they are representative for other varieties with similar heading potential. Thus in Nandi III, Pokot Rhodes and Makueni Guinea, the percentage of heading tillers either in number or in dry weight did not exceed $50 \%$ of the total (Fig. 1, Tables 3 and 4). These are all sparsely heading varieties whether early or late heading (Fig. 2). The opposite applied to the profusely heading varieties such as Coloured Guinea and Congo Signal. It is also evident that an intermediate group is represented by Mbarara and Masaba Rhodes and Nandi I.

After the maximum tiller number had been reached, numbers decreased almost as rapidly as they had increased at first, but levelled off 1-2 months later. Final numbers were similar in most varieties. In contrast, numbers of non-heading tillers decreased

Table 4. Maximum dry weight of tillers and heading tillers $(\mathrm{kg} / \mathrm{ha})$.

\begin{tabular}{|c|c|c|c|c|c|c|}
\hline \multirow[t]{2}{*}{ Variety } & \multicolumn{3}{|l|}{1968} & \multicolumn{3}{|l|}{1969} \\
\hline & tillers & $\begin{array}{l}\text { heading } \\
\text { tillers }\end{array}$ & $\%$ & tillers & $\begin{array}{l}\text { heading } \\
\text { tillers }\end{array}$ & $\%$ \\
\hline Nandi I & 10,720 & 5,030 & 47 & 8,130 & 5,450 & 67 \\
\hline Nandi III & 10,000 & 3,330 & 33 & 7,750 & 3,000 & 39 \\
\hline Mbarara Rhodes & 11,000 & 5,370 & 49 & 7,750 & 4,500 & 58 \\
\hline Masaba Rhodes & 12,200 & 7,130 & 58 & 7,120 & 3,400 & 48 \\
\hline Pokot Rhodes & 11,690 & 5,600 & 48 & 7,500 & 3,020 & 40 \\
\hline Coloured Guinea & 8,250 & 5,530 & 67 & 7,100 & 6,250 & 88 \\
\hline Makueni Guinea & 5,540 & 1,280 & 23 & 4,860 & 2,230 & 46 \\
\hline Congo Signal & 12,200 & 7,400 & 61 & 7,350 & 5,840 & 79 \\
\hline
\end{tabular}




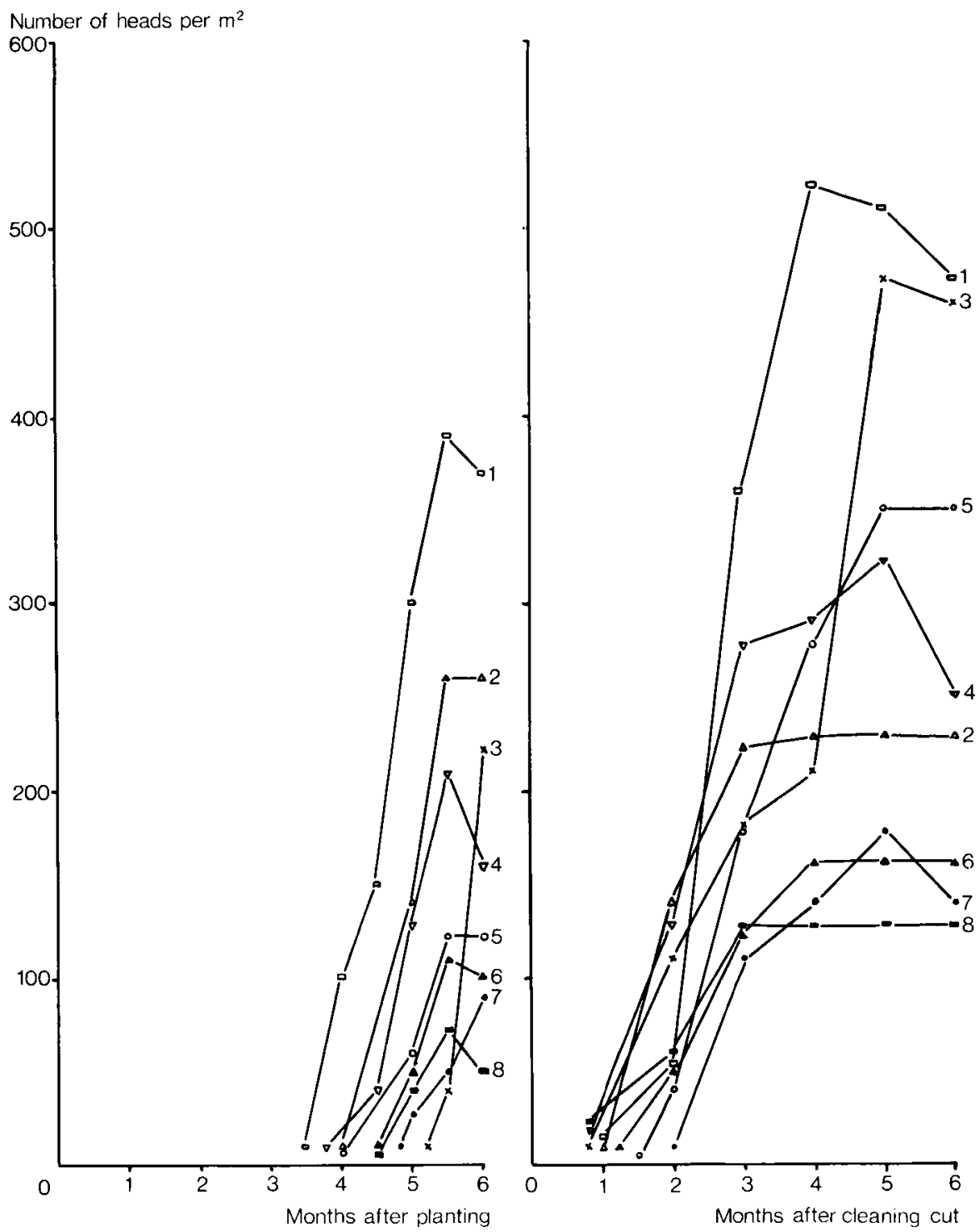

Fig. 2. Patterns of head emergence in 1968 (left) and 1969 (right). $1=$ Coloured Guinea; $2=$ Masaba Rhodes; $3=$ Congo Signal; $4=$ Mbarara Rhodes; $5=$ Nandi I; $6=$ Pokot Rhodes; $7=$ Nandi 11I; 8 = Makueni Guinea.

most rapidly in varieties producing many heads, owing to the change-over from nonheading to heading tillers (Fig. 1). The complete set of data for head emergence in both years is presented in Fig. 2. It is evident that head numbers increased at an apparently linear rate for a considerable length of time. In 1968, this varied from one 
month in Makueni Guinea and Pokot Rhodes to two months in Coloured Guinea and Mbarara Rhodes. In 1969, heading proceeded at a linear rate over a period ranging from 2 months in Makueni Guinea and Mbarara and Masaba Rhodes to 31/2 months in Nandi 1 .

The highest numbers of heads were produced in 1968 by Coloured Guinea (390) and in 1969 by Coloured Guinea (520) and Congo Signal (470). Nandi I produced more heads than the late-heading Nandi III, and the late-heading Pokot Rhodes produced fewer heads than Mbarara and Masaba Rhodes. Numbers were generally higher in 1969 than in 1968 except in Masaba Rhodes.

\section{Weight of tillers}

The curves representing increase in dry weight of tillers and heading tillers were parallel, a rapid initial increase being followed by a gradual levelling off (Fig. 1). Clear differences between varieties arose. In the sparsely heading Nandi III, maximum weight of heading tillers only comprised $39 \%$ of the maximum total dry weight of tillers, whereas this proportion amounted to $58 \%$ in Mbarara Rhodes and even as much as $88 \%$ in Coloured Guinea (Table 4). Alternatively, weight of non-heading tillers dropped markedly in the last two varieties after having reached a maximum in the period of early heading.

As mentioned earlier, Pokot Rhodes and Makueni Guinea reacted similarly to Nandi III in both years, while Congo Signal joined the side of Coloured Guinea. How the other varieties reacted in both years is shown in Table 4 . The percentage weight of heading tillers shows whether and to what extent this weight exceeded the weight of non-heading tillers.

Total dry weights of tillers were considerably higher in 1968 than in 1969. Coloured Guinea and Makueni Guinea were the lowest yielding which confirms the empirical experience. Yield differences in the other varieties over both years were slight, but Nandi I outyielded Nandi III consistently and also reached a given weight at an earlier date.

The important differences between varieties arose from the different weight proportions of heading and non-heading tillers. Thus throughout the heading period, a larger proportion of non-heading tillers was maintained by Nandi III, Pokot Rhodes and Makueni Guinea than by Nandi I, the other Rhodes varieties and Coloured Guinea, respectively. As noted earlier, the first group of varieties is characterized by limited heading either early or late.

On the other hand it is important to note that all three Rhodes varieties and Nandi I exceeded the level of $5000 \mathrm{~kg} / \mathrm{ha}$ dry weight of non-heading tillers in 1969 within 8 weeks after the cleaning cut. The level of $5000 \mathrm{~kg} / \mathrm{ha}$ of total dry weight of tillers was reached within 5 weeks after the cleaning cut in Masaba and Pokot Rhodes pointing to a average growth rate of $140 \mathrm{~kg} \mathrm{DM} \mathrm{ha}^{-1} \mathrm{day}^{-1}$. This amount does not include the dead material and loose leaves which were discarded for the purpose of this study, although they amounted to about $10 \%$ of the total dry matter.

The dry weight per tiller was calculated on the basis of overall tiller numbers and weights. Total dry weights of tillers were higher in 1968 (Table 4), but tiller numbers were lower (Table 3), so that the weight per tiller was considerably higher in the year of planting (Table 5). It can be seen from Fig. 1 that the weight per tiller increased at a linear rate with a slight tendency to level off at the later stages of sampling. Varieties with similar weights of tillers but smaller tiller numbers had markedly heavier tillers, as is borne out in Table 5 . 
Table 5. Weight per tiller (mg) at IHE date of the earliest varieties.

\begin{tabular}{lcl}
\hline Variety & $22-7-' 68$ & 3-6-'69 \\
Nandi I & 760 & 260 \\
Nandi III & 390 & 220 \\
Mbarara Rhodes & 970 & 210 \\
Masaba Rhodes & 1,160 & 190 \\
Pokot Rhodes & 1,640 & 260 \\
Coloured Guinea & 520 & 200 \\
Makueni Guinea & 400 & 280 \\
Congo Signal & 910 & 280 \\
\hline
\end{tabular}

It follows that tillers were much heavier in 1968 than in 1969, and that varieties with fewer tillers produced heavier tillers. Consequently, tillers were heavier in Nandi I than in Nandi III and heavier in Pokot than in Mbarara or Masaba Rhodes.

\section{Culm length and culm branching}

Data on mean culm length were obtained from 25 culms taken at random at each sampling cut in 1969 (Fig. 4).

Mean culm length increased rapidly at first and tended to level off about 16 weeks after the cleaning cut. The increase was most pronounced in Nandi, moderate in Rhodes and Coloured Guinea and only slight in Makueni Guinea. Among Rhodes varieties Mbarara Rhodes produced the longest culms. Nandi I produced longer culms than Nandi III. The longest culms were produced by Makueni Guinea followed by Nandi I.

In Coloured Guinea and Nandi it was often observed that tillers arising from elevated nodes of erect parental culms developed into flowering culms, which in turn developed nodal tillers and culms. In some instances two culms were found to arise from one single node of a parental culm. Thus far, up to eight culms have been found originating from one single tiller. Under such circumstances one could expect to find
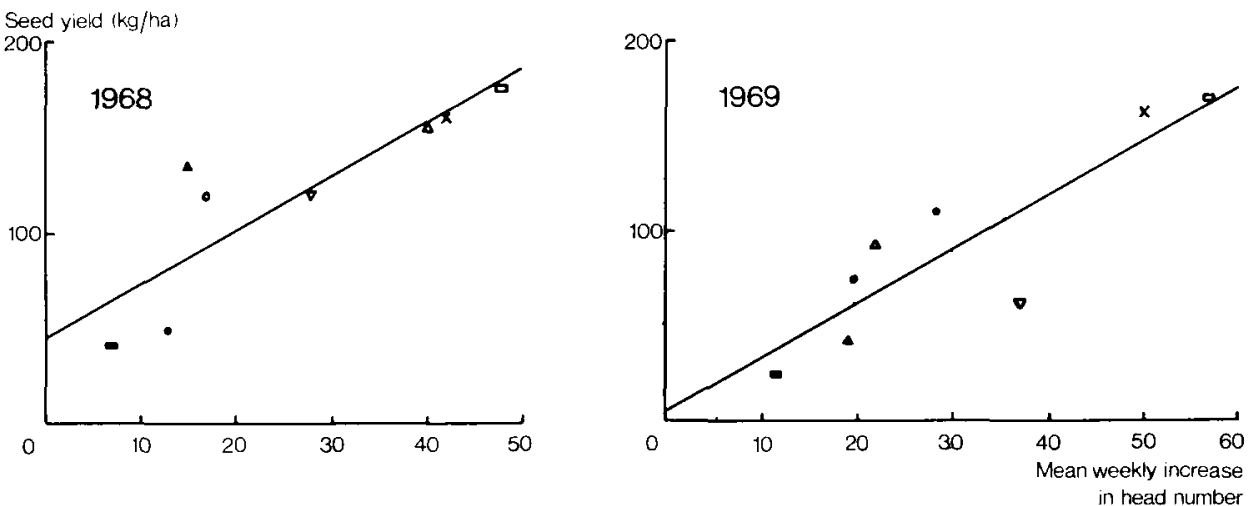

Fig. 3. The relation between maximum seed yield and mean weekly increase in head numbers prior to optimal harvesting time. For explanation of symbols, see Fig. 2. Left: 1968 ( $y=2.8 x+46.0$; $\left.\mathrm{r}_{6}=0.85\right)$; right : $1969\left(\mathrm{y}=2.9 \mathrm{x}+4.6 ; \mathrm{r}_{\mathrm{b}}=0.88\right)$. 


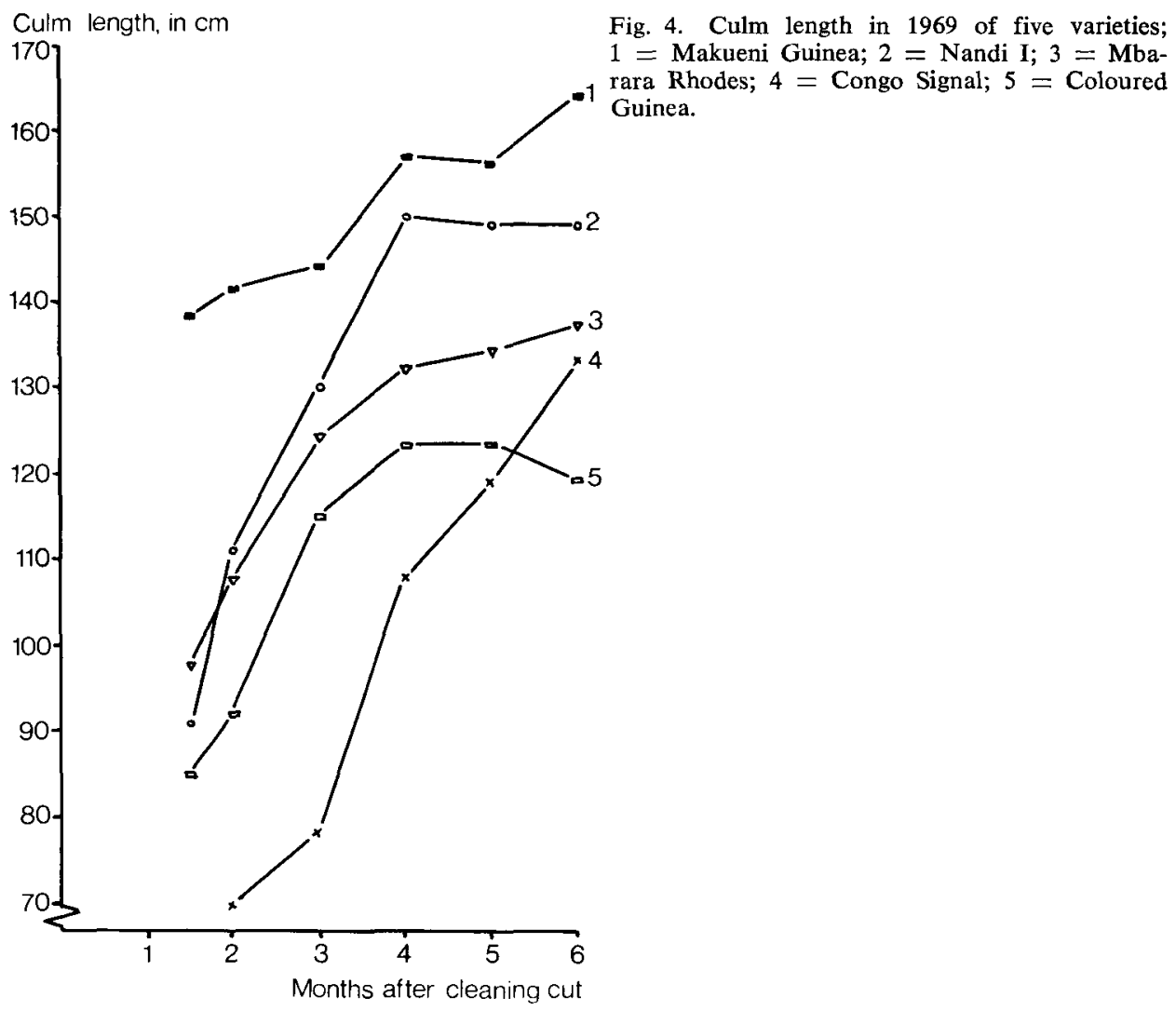

higher numbers of tillers than when each tiller had given rise to only one heading tiller. At this stage it is also important to mention the irregular tillering pattern of Congo Signal in 1969. It can be seen from Fig. 2 that a second rapid increase in head numbers took place between 4 and 5 months after the cleaning cut. This was associated with a rapid drop in numbers and weights of non-heading tillers which had been increasing in the previous weeks, although heading had already started in the third week. The tillering patterns of Congo Signal in 1969 were therefore characterized by having two peaks instead of just one.

The correlation between heading pattern and seed yield

Concurrent with the present study on tillering and heading, an attempt was made to study the effect of a wide range of harvesting times on seed yield in order to determine the optimal harvesting time. By so doing, it was possible to correlate the seed yields obtained at optimal harvesting time with the tillering and heading characteristics of the eight grass varieties.

It is evident from Table 6 that seed yields of varieties were closely correlated with their heading characteristics but not with tiller numbers. The closest correlation achieved was the one between seed yield and the mean weekly increase in head number over the period of six weeks prior to optimal harvesting time. This mean increase can be 
Table 6. The correlation coefficients between a) seed yield and b) tillering and heading characteristics of eight grasses ( $r$ has 6 degrees of freedom).

\begin{tabular}{lcc}
\hline Between seed yield and & Correlation coefficient (r) \\
\cline { 2 - 3 } & 1968 & 1969 \\
& -0.22 & -0.07 \\
Maximum tiller number & 0.03 & -0.11 \\
Tiller number at optimal harvesting time & $0.80^{*}$ & $0.82^{*}$ \\
$\begin{array}{l}\text { Head number at optimal harvesting time } \\
\text { Percentage of tillers heading at optimal } \\
\text { harvesting time }\end{array}$ & $0.81^{*}$ & $0.84^{* *}$ \\
$\begin{array}{l}\text { Tillers heading at optimal harvesting time } \\
\text { as percentage of the maximum number }\end{array}$ & $0.76^{*}$ & $0.77^{*}$ \\
$\begin{array}{l}\text { Mean weekly increase in head number } \\
\text { prior to optimal harvesting time }\end{array}$ & $0.85^{* *}$ & $0.88^{* *}$ \\
\hline
\end{tabular}

taken to represent the degree of concentrated head emergence of a variety. In both years Coloured Guinea showed the highest degree of concentrated head emergence and achieved the highest seed yield of all varieties. The opposite applied to Makueni Guinea (Fig. 3).

\section{Discussion}

Tillering is a dynamic process involving tiller formation and death, so that counts of tillers are only a census of an ever-changing population.

Tiller numbers rose to a maximum which roughly coincided with the period of IHE followed by a decline (Fig. 1). The patterns of tillering were similar to those observed in temperate grasses (Langer et al., 1964) and cereals (Bunting and Drennan, 1966).

Reporting on the decline in tiller numbers he observed in Festuca rubra, Sonneveld (1962) concluded that tiller formation stopped following elongation of flowering culms and that part of the tillers was even emptied and spent. Reviewing literature on this subject, Humphreys (1966a) pointed out that inhibition of tillering has often been related to the onset of the reproductive stage, the effect disappearing during seed maturation.

In the present study some indications arose to the effect that decreased tillering can not be explained on the basis of elongation only. First of all, the drop in tiller numbers was very marked (Fig. 1) although the onset of heading was gradual. Secondly, the phenomenon of culm branching shows that tiller formation can indeed continue on elongating flowering culms. Thirdly, a second peak of tillering and heading was observed in 1969 in Congo Signal, some two months after the first peak. Reviewing the present stage of knowledge on tillering, Dorrington Williams (1970) states that it is as yet unclear whether tiller production during flowering is suppressed by apical dominance or by insufficient light. He goes on that the onset of reproductive development is accompanied by suppression of buds borne on the flowering axes; the continued growth and production of already existing vegetative tillers can at the same time be suppressed by the reduction in light intensity resulting from the extension growth of reproductive tillers. On account of the above indications it is therefore likely that the decline in numbers was caused by reduced light intensity, the effect disappearing of the seed crop matured. 
The phenomenon of culm branching as observed in Coloured Guinea and Nandi, with 'secondary' culms developing without rooting on nodes of erect flowering culms, shows that tillers can complete elongation and heading while being dependent on a parental culm. 'Secondary' culms were found to produce 'tertiary' culms. This is not in agreement with the suggestion put forward by Jewiss (1966) that tillers must be selfsupporting before they themselves produce subsidiary tillers. It further shows that tiller formation is not necessarily stopped when the parental shoot begins elongation. Heading tillers elongating from elevated nodes on parent tillers have also been noticed in barley by Aspinall (1961). No references to culm branching in grasses were found, but Dirven (personal communication) also noticed culm branching in Coloured Guinea in Surinam.

Sparsely heading varieties such as Nandi III, Pokot Rhodes and Makueni Guinea appeared to maintain a dominant percentage of numbers and weights of non-heading tillers (Fig. 1, Tables 3 and 4). In profusely heading varieties such as Coloured Guinea and Congo Signal, numbers and weights of heading tillers overtook those of non-heading tillers. The occurrence of a dominant percentage of non-heading tillers does not necessarily imply that the particular variety is late-heading.

In the year of planting tillers developed on seedlings and the maximum number found did not exceed 800 per $\mathrm{m}^{2}$ (Table 3). In the following year, 1000 or more tillers were already recorded in most varieties within two weeks after the cleaning cut (Fig. 1). Many of these were carried over from the preceding crop in a vegetative stage which was evident from the cutting marks.

The interval between cleaning cut and IHE was very short in 1969, e.g., three weeks in Mbarara Rhodes and six weeks in Nandi I (Fig. 2). This interval can be as long as 12 weeks when the preceding crop is cut at the usual stage of seed harvesting, as experienced in commercial practice. Regrowth and subsequently date of IHE appear to be delayed if the cleaning cut is carried out at an advanced stage of heading. In 1969 the cleaning cut concerned crops at the stage of early heading. According to Langer (1957), high tiller numbers produced early in the season ensure maximum regrowth. It is further evident from Fig. 1 that maximum tiller numbers were produced around IHE. Hence, it is likely that when a crop is cut at the early heading stage, regrowth will be faster and subsequent date of IHE attained earlier than when cut at a more advanced stage. It has been reported above that the regrowth amounted to over $140 \mathrm{~kg} \mathrm{ha}^{-1}$ day-1 over the 5-week period after the cleaning cut in Pokot and Masaba Rhodes.

The sequence in which varieties start IHE depends on the kind of variety. It can be seen from Table 2 that Nandi I headed 1-3 weeks earlier than Nandi III. Mbarara Rhodes was earlier than Masaba which, in turn, headed earlier than Pokot. As in temperate grasses, heading date could be an important aid to the identification of varieties.

Another tool for varietal identification is provided by the differences in tiller numbers and weights (Fig. 1, Tables 3 and 5). Pokot Rhodes consistently showed fewer, but heavier tillers than either Mbarara or Masaba Rhodes. Nandi I produced fewer but heavier tillers than Nandi III.

In the year of planting, 1968, tillering was limited in number, but tillers were much heavier than in the second year (Tables 3 and 5). Equally, varieties with inherently smaller tiller numbers than other varieties of the same species still produced as much or even more herbage dry matter because the greater tiller weight made up for the smaller number of tillers. Because of this compensatory effect between tiller number and weight, it seems that tiller numbers, as such, can provide little information on yield. 
The maximum tiller numbers found in this study were about 1,900 per $\mathrm{m}^{2}$ in Nandi III, 1,400 in Nandi I and 1,600 in Mbarara Rhodes (Table 3). In experiments involving various row densities and levels of nitrogenous fertilizer, up to 2,800 tillers per $\mathrm{m}^{2}$ have been recorded in Nandi II and up to 2,300 in Mbarara Rhodes (Boonman, unpublished data). Also Singh and Chatterjee (1966) found up to 2,000 tillers per $\mathrm{m}^{2}$ in swards of an unspecified Rhodes grass variety originating from Kenya. In contrast, temperate grasses produce much higher numbers of tillers. In experiments on timothy and meadow fescue, Langer et al. (1964) observed 5,000-8,000 tillers per $\mathrm{m}^{2}$ in established swards, although much higher numbers were found in the winter months after sowing. Fine tillered species such as Poa trivialis, Agrostis stolonifera and Festuca rubra are generally known to produce over 10,000 tillers per $\mathrm{m}^{2}$.

It is evident from Fig. 3 that seed yield is closely correlated with the degree of concentrated heading, the percentage of heading tillers and head number. As shown in Fig. 2 head emergence may continue for 3-4 months. The optimal time of harvesting is usually reached at an early stage when head numbers are still on the increase (Boonman, unpublished data). The highly significant Correlation Coefficients $\left(r_{6}=0.85\right.$ in $1968 ; r_{6}=0.88$ in 1969) between seed yield and degree of concentrated heading up to harvesting time indicate that prolonged heading is a major cause of low seed yield encountered in tropical grasses.

Also important is the evidence adduced (Table 6) that high tiller numbers do not necessarily lead to high numbers of heads and high seed yield. In this respect, Nandi and Rhodes showed a contrasting relationship. In Rhodes grass, Mbarara and Masaba Rhodes produced more, albeit lighter, tillers, more heads and higher seed yields than the late heading Pokot Rhodes. In contrast, the late heading Nandi III produced more and finer tillers, but less heads and less seed than Nandi I. The three varieties of Rhodes grass were developed from entirely different ecotypes, whereas Nandi III was developed out of Nandi I (Bogdan, 1966). From the breeding point of view it is therefore tempting to suggest that plants with heavier tillers may produce many heads and high seed yields compared to the average of a population. This is also supported by the evidence noted above, that varieties produced higher seed yields in the year of planting when tillers were less numerous but heavier and producing longer heads when compared with the subsequent year.

In grasses of temperate climates, differences between heads in the date of head emergence are only a few days, whereas the tillers producing them originate over a long period from early autumn onwards (Ryle, 1966). Photoperiod is the main factor determining the time of head initiation in temperate grasses, causing tillers of very different ages to elongate and head within a very short period. In tropical grasses, however, tillering and heading both appear to be prolonged processes.

\section{References}

Aspinall, D., 1961. The control of tillering in the barley plant. 1. The pattern of tillering and its relation to nutrient supply. Aust. J. biol. Sci. 14: 493-505.

Bogdan, A. V., 1966. Plant introduction, selection, breeding and multiplication. In: W. Davies \& C. L. Skidmore (Ed.), Tropical pastures. Faber \& Faber, London.

Boonman, J. G., 1971. Experimental studies on seed production of tropical grasses in Kenya. 1. General introduction and analysis of problems. Neth. J. agric. Sci. 19: 23-36.

Bunting, A. H. \& D. S. H. Drennan, 1966. Some aspects of the morphology and physiology of cereals in the vegetative phase. In: F. L. Milthorpe \& J. D. Ivins (Ed.), The growth of cereals and grasses. Butterworths, London. 
Chatterjee, B. N. \& R. D. Singh, 1968. Growth analysis of perennial grasses in the tropics in India. IV. Changes in the tiller population in grass swards. Allahabad Fmr 42: 65-73.

Dorrington Williams, R., 1970. Tillering in grasses cut for conservation, with special reference to perennial ryegrass. Review article. Herb. Abstr. 40:383-388.

Haggar, R. J., 1966. The production of seed from Andropogon gayanus. Proc. int. Seed Test. Ass. 31: $251-259$.

Humphreys, L. R., 1966a. Pasture defoliation practice: a review. J. Aust. Inst. agric. Sci. 32: 93-105.

Humphreys, L. R., 1966b. Subtropical grass growth. 3. Effects of stage of defoliation and inflorescence removal. $Q d$ J. agric. Anim. Sci. 23: 499-531.

Jewiss, O. R., 1966. Morphological and physiological aspects of growth of grasses during the vegetative phase. In: F. L. Milthorpe \& J. D. Ivins (Ed.). The growth of cereals and grasses. Butterworths, London.

Langer, R. H. M., 1957. Growth and nutrition of timothy (Phleum pratense). II. Growth of the plant in relation to tiller development. Ann. appl. Biol. 45: 528-541.

Langer, R. H. M., 1963. Tillering in herbage grasses. Review article. Herb. Abstr. 33: 141-148.

Langer, R. H. M., S. M. Ryle \& O. R. Jewiss, 1964. The changing plant and tiller population of timothy and meadow fescue swards. 1. Plant survival and the pattern of tillering. J. appl. Ecol. 1: 197-208.

Ryle, G. J. A., 1966. Physiological aspects of seed yield in grasses. In: F. L. Milthorpe \& J. D. Ivins (Ed.), The growth of cereals and grasses. Butterworths, London.

Singh, R. D. \& B. N. Chatterjee, 1966. Tillering of perennial grasses in the tropics in India. Proc. 9th int. Grassld Congr. 1965: 1075-1079.

Sonneveld, A., 1962. Distribution and re-distribution of dry matter in perennial fodder crops. Neth. J. agric. Sci. $10: 427-444$. 